\title{
Impact of selected parameters on the development of boiling and flow resistance in the minichannel
}

\author{
Magdalena Piasecka ${ }^{1, a}$ and Kinga Ziętala ${ }^{2}$ \\ ${ }^{1}$ Kielce University of Technology, Faculty of Mechatronics and Machine Design, Al. 1000-lecia P.P. 7, 25-314 Kielce, Poland \\ ${ }^{2}$ Kielce University of Technology, Faculty of Environmental Engineering, Geomatic and Energy Engineering, Al. 1000-lecia P.P. 7 , \\ 25-314 Kielce, Poland
}

\begin{abstract}
The paper presents results of flow boiling in a rectangular minichannel $1 \mathrm{~mm}$ deep, $40 \mathrm{~mm}$ wide and $360 \mathrm{~mm}$ long. The heating element for FC-72 flowing in the minichannel was the thin alloy foil designated as Haynes-230. There was a microstructure on the side of the foil which comes into contact with fluid in the channel. Two types of microstructured heating surfaces: one with micro-recesses distributed evenly and another with minirecesses distributed unevenly were used. The paper compares the impact of the microstructured heating surface and minichannel positions on the development of boiling and two phase flow pressure drop. The local heat transfer coefficients and flow resistance obtained in experiment using three positions of the minichannel, e.g.: $0^{\circ}, 90^{\circ}$ and $180^{\circ}$ were analyzed. The study of the selected thermal and flow parameters (mass flux density and inlet pressure), geometric parameters and type of cooling liquid on the boiling heat transfer was also conducted. The most important factor turned out to be channel orientation. Application of the enhanced heating surface caused the increase of the heat transfer coefficient from several to several tens per cent, in relation to the plain surface.
\end{abstract}

\section{Introduction}

Heat transfer in small channels has been studied intensively over the last few years, especially as regards the application in cooling electronic components. Mini heat exchangers are used to provide higher cooling capability for new technologies. It means reducing their sizes and costs, while the consumed power is identical. Owing to the change of the state which accompanies flow boiling in small channels, it is feasible to meet contradictory needs simultaneously, i.e. obtain a heat flux as large as possible at small temperature difference between the heating surface and the saturated liquid while retaining small dimensions of heat transfer systems. The use of microstructured surfaces allows additional intensification of the process that have been reported for pool boiling [1-3] or for heat exchangers [4]. An important issue for minichanels is pressure drop [5].

The series of studies pursued at the Kielce University of Technology includes research on flow boiling heat transfer in a cooling fluid flow along the minichannel with plain or microstructured heating walls and various orientations. The results were described in numerous publications [6-11].

This paper compares the impact of type of enhanced heating surface, orientation of the minichannel and selected thermal and flow parameters on the development of boiling and two phase pressure drop in the minichannel.

\footnotetext{
${ }^{a}$ Corresponding author: tmpmj@tu.kielce.pl
}

\section{Experimental set-up and procedure}

The essential part of the experimental set-up is the test section with a rectangular minichannel $1 \mathrm{~mm}$ deep, $40 \mathrm{~mm}$ wide and $360 \mathrm{~mm}$ long, figure 1 . The heating element for FC-72 flowing in the minichannel is $0.1 \mathrm{~mm}$ thick foil made from Haynes-230 alloy. There is a microstructure on the side of the foil which contacting with fluid in the channel. It is possible to observe both surfaces of the channel through glass panes. One pane allows observing changes in the temperature distribution on the plain side of the foil thanks to the liquid crystal thermography. The latter one allows observing the twophase flow patterns on the microstructured foil side. K-type thermocouples and pressure converters are installed at the inlet and outlet of the minichannel.

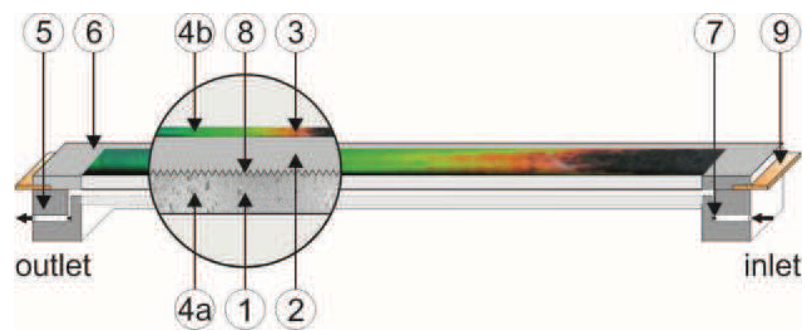

Figure 1. The schematic diagrams of the measurement module: 1 - minichannel, 2 - heating foil, 3 - liquid crystal layer, 4a,b -glass sheet, 5 - channel body, 6 - front cover, 7 - thermocouple, 8 - enhanced surface, 9 - copper element 
Two types of microstructured heating surfaces were used: one with micro-recesses distributed evenly (four laser texturing), and another with mini-recesses distributed unevenly [12], figure 2 .

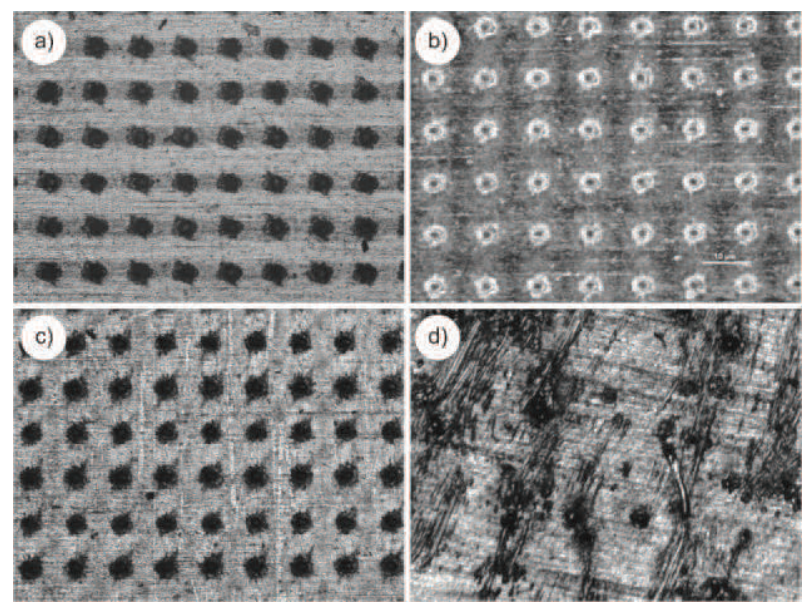

Figure 2. Photo of the sampled area with a), b) c) three types of micro-recesses, b) mini-recesses

The micro-recesses (figure 2a) were performed by laser drilling. The diameter of the single micro-recess is usually $10 \mu \mathrm{m}$, its depth is $3 \mu \mathrm{m} .5 \div 7 \mu \mathrm{m}$ high layers of melted metal deposit annularly around the recesses, forming structures that can be named as "craters". Micro-recesses are evenly distributed every $100 \mu \mathrm{m}$ in both axes. The mini-recesses (figure $2 \mathrm{~d}$ ) were obtained by spark erosion. The melted metal foil and electrode material, a few $\mu \mathrm{m}$ high, reaching locally $5 \mu \mathrm{m}$, accumulate around the recesses. The depth of the cavity craters is usually below $1 \mu \mathrm{m}$.

The measurement module with a minichannel was oriented at various inclination angles, i.e. 0, 45, 90, 135 and 180 degrees inclinations in relation to the horizontal plane, as shown in figure 3 . Three the most important positions were: the horizontal orientations: positions $0^{\circ}$ and $180^{\circ}$ and the vertical orientation, position $90^{\circ}$.

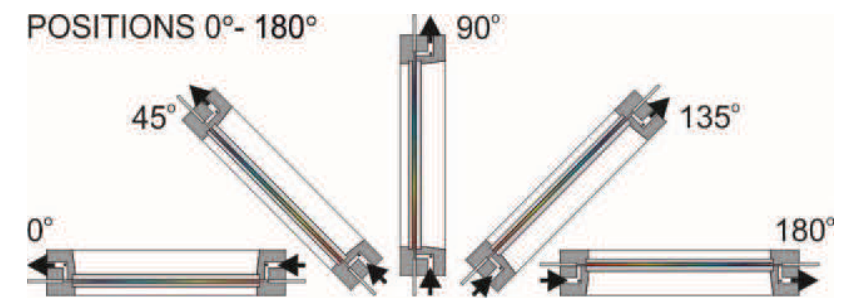

Figure 3. Positions of the minichannel used in experiments

Main loops of the experimental set-up are presented in detail in previous publications $[6,8-10]$. The flow loop consists of: the test section, the rotary pump, the compensating tank, the heat exchanger, the filter, rotameters and the deaerator. The data and image acquisition system include: two digital cameras, lighting system, data acquisition station and a laptop.
After deaeration of the main loop, working fluid (FC-72) flows laminarly along the minichannel. When the desired pressure and flow rate are reached, the gradual increase in the electric power supplied to the heating foil results in an increased heat flux transferred to the fluid in the channel. This leads to the incipience and then to the development of nucleate boiling. Thanks to the liquid crystal layer located on its surface contacting the glass it is possible to measure the temperature distribution on the heating wall. Flow structure is observed simultaneously in the opposite side of the minichannel. Uncertainty analyses including evaluation of the accuracy of heating foil temperature measurements with liquid crystals thermography was presented in detail in [13].

Various methods of the determination of the local heat transfer coefficient in the two-dimensional approaches were proposed $[8,11]$. Here, the simple onedimensional approach was used [7, 14]. The resulting heat transfer coefficient for the subcooled boiling was determined as follows:

$$
\alpha(x)=\frac{I \cdot \Delta U / A_{F}}{T_{F}(x)-T_{f}(x)-\frac{I \cdot \Delta U}{A_{F}} \cdot \frac{\delta_{F}}{\lambda_{F}}} .
$$

For the saturated boiling local heat transfer coefficients were calculated according to the following equation:

$$
\alpha(x)=\frac{I \cdot \Delta U / A_{F}}{T_{F}(x)-T_{s a t}(x)-\frac{I \cdot \Delta U}{A_{F}} \cdot \frac{\delta_{F}}{\lambda_{F}}},
$$

where $I$ - current, $U$ - voltage drop, $A_{F}$ - foil surface, $\lambda_{F}-$ foil thermal conductivity, $\delta_{F}-$ foil thickness, $T_{F}$ - foil temperature, $T_{f}$ - fluid temperature calculated with the assumption of linear temperature distribution of the fluid flowing along the minichannel (measurement of the liquid temperature at minichannel inlet and outlet), $T_{\text {sat }}$ - saturation temperature determined on the basis of the linear pressure distribution, from the inlet to the outlet, $x$ - the distance from the channel inlet to outlet.

\section{Results}

\subsection{The impact of microstructured heating surface on heat transfer coefficient}

The results adopted for the analysis are presented as heat transfer coefficient dependence on the distance along the minichannel length, figure 4 , data (a). The data was obtained using various heating foils: plain and enhanced with micro-recesses (produced on the whole area of the foil) and mini-recesses (made on the selected area or on the whole area of the foil). During experimental series the heat flux density was identical and similar thermal-flow parameters were set. 


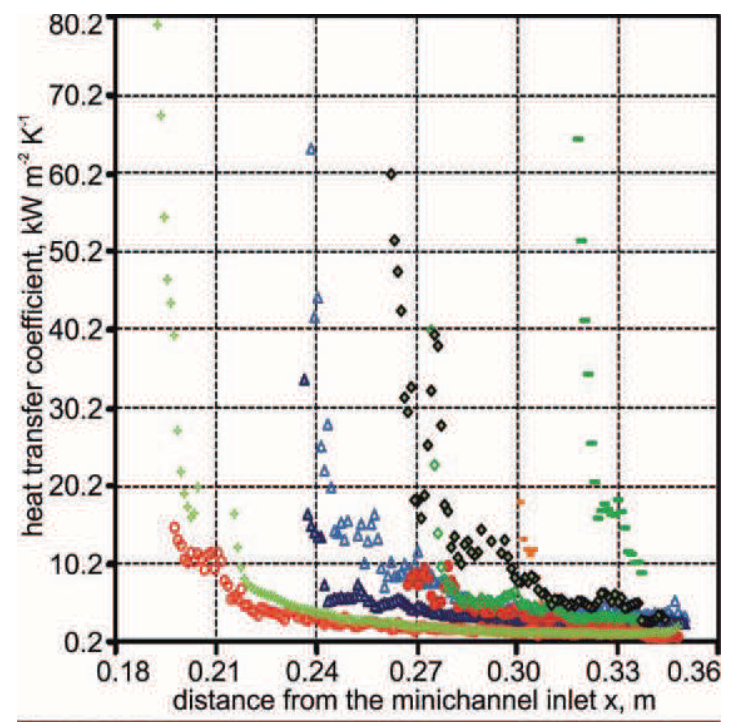

a) $\begin{aligned} & \mathrm{G}=286 \mathrm{~kg} \mathrm{~m}^{-2} \mathrm{~s}^{-1} ; p_{\text {in }}=120 \div 130 \mathrm{kPa} ; q_{\mathrm{w}} \approx 21.5 \mathrm{~kW} \mathrm{~m}^{-2} \\ & \text { micro-recesses on the whole area of the foil } \\ & \text { - } \text { mini-recesses on the selected area of the foil } \\ &- \text { mini-recesses on the whole area of the foil } \\ & \text { - plain foil }\end{aligned}$

Figure 4. Heat transfer coefficient dependence on the distance along the minichannel length, obtained for analysis when similar thermal-flow parameters (mass flux density $G$, inlet pressure $p_{i n}$ ) and identical heat flux density $q_{w}$ and:

(a) various heating foils: plain and enhanced with micro- or mini-recesses (produced on the selected or whole heating area),

(b) the heating foil with micro-recesses and mini-recesses,

(c) the heating foil with micro-recesses on the whole area of the foil, channel positioned differently,

were used in experiments

After analyzing these results it was noticed that using of enhanced heating foils resulted in an increase of the heat transfer coefficient from several to several dozen per cent (nearly twice for the highest values of the coefficient) in relation to the plain surface.

Surfaces with evenly distributed micro-recesses enabled obtaining heat transfer coefficient values higher than those for the surface with unevenly distributed minirecesses, figure 4 , data (b).

\subsection{The impact of channel position on heat transfer coefficient}

The results taken for the analysis are presented as heat transfer coefficient dependence on the distance along the minichannel length. Three position of the channel, e.g.: $0^{\circ}, 90^{\circ}$ and $180^{\circ}$ were set for comparative analysis, figure 4 , data (c). These are data obtained at similar thermal-flow parameters and heat flux density when the same foil with micro-recesses was applied.

It can be noticed that the highest heat transfer coefficient values were observed in the vertical orientation, position $90^{\circ}$, slightly lower for the horizontal orientation, position $0^{\circ}$. The lowest values of the local heat transfer coefficient were observed for the horizontal orientation, position $180^{\circ}$. The similar results were described in [14].

\subsection{The impact of the channel orientation on flow resistance}

The impact of the channel orientation on flow resistance was analyzed on the basis of experimental data, which are shown below in figure 5, additionally for: the horizontal orientation (position $0^{\circ}$ ) - figure $5 \mathrm{a}$, the vertical orientation (position $90^{\circ}$ ) - figure $5 \mathrm{~b}$ and the horizontal orientation (position $180^{\circ}$ ) - figure $5 \mathrm{c}$.

The highest flow resistance was recorded in the vertical orientation (position $90^{\circ}$ ), while the lowest flow resistance was recorded in the horizontal orientation of the channel, (position $180^{\circ}$ ); and this data was obtained at lowest heat fluxes supplied to the heating surface.
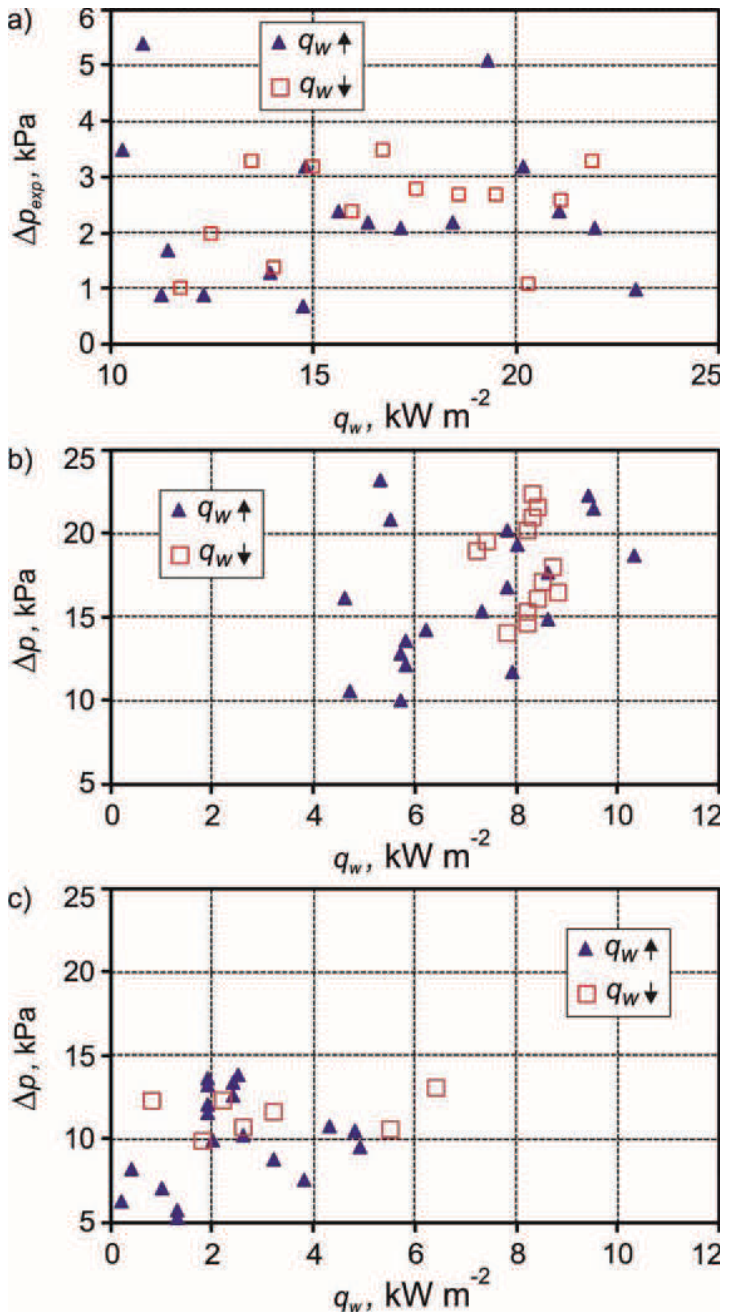

Figure 5. Flow resistance dependence in the function of heat flux density, obtained for similar inlet pressure and mass flux densities when the heating foil with micro-recesses was applied in experiments, data for: a) the horizontal minichannel (position $0^{\circ}$ ), b) the vertical minichannel (position $90^{\circ}$ ), c) the horizontal minichannel (position $180^{\circ}$ ); experimental parameters: mass flux density $G=211 \mathrm{~kg} \mathrm{~m}^{-2} \mathrm{~s}^{-1}$, inlet pressure $p_{\text {in }}=125 \mathrm{kPa}$ 


\subsection{The impact of channel orientation on boiling curves}

Boiling curves are obtained on the basis of data, while increasing and later decreasing the heat flux supplied to the heating foil. They are usually constructed for the selected points in the channel (at selected distance from the inlet), where heat flux density depends on the heating surface superheating or on the difference $T_{F}-T_{f}$, as presented in figure 6 . The results taken for the analysis are presented as boiling curves obtained for three position of the channel, e.g.: $0^{\circ}, 90^{\circ}$ and $180^{\circ}$ were set for comparative analysis. They are constructed for three points (located centrally in the channel axis) from the minichannel inlet: $0.059 \mathrm{~m}, 0.103 \mathrm{~m}$ and $0.139 \mathrm{~m}$. Unfortunately, the full course of the lower section of the curve presented in figure 6 cannot be observed (absence of data on foil temperature - measurement impossible with the liquid crystal paint used during experiment).
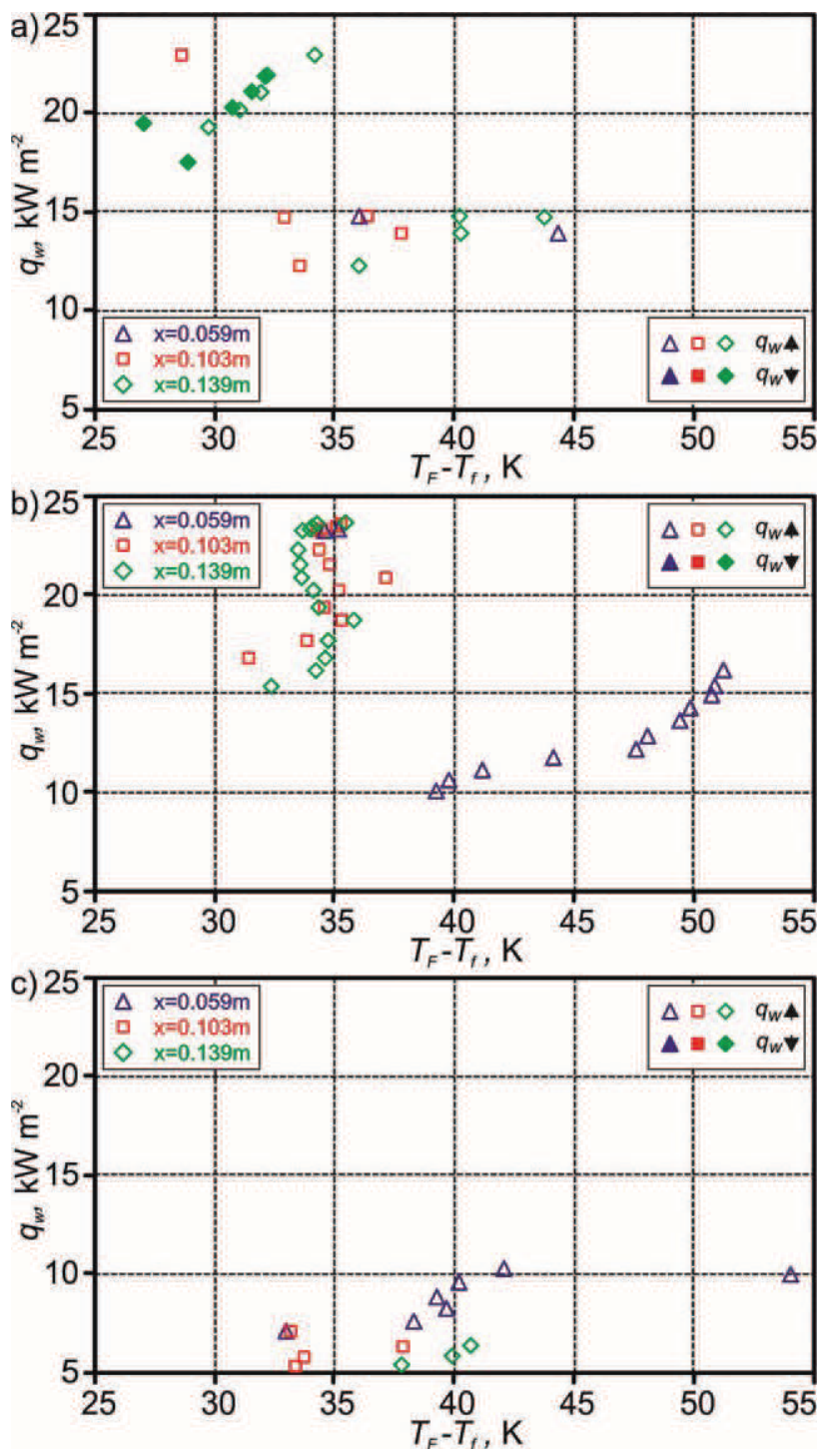

Figure 6. Boiling curves for three constant distances from the minichannel inlet: $0.059 \mathrm{~m}, 0.103 \mathrm{~m}$ and $0.139 \mathrm{~m}$; data for: a) the horizontal minichannel (position $0^{\circ}$ ), b) the vertical minichannel (position $90^{\circ}$ ), c) the horizontal minichannel (position $180^{\circ}$ ); experimental parameters as for figure 5
When analyzing courses of boiling curves it was found that in the vertical orientation of the channel $\left(\right.$ position $90^{\circ}$ ) and horizontal orientation (position $0^{\circ}$ ) the resultant heat flux supplied to the heating surface seemed to be considerably higher in comparison to flux values recorded for the horizontal channel (position $180^{\circ}$ ). Other remarks are ambiguous.

In earlier paper [6] it was found that incipience and development of boiling when the enhanced surface is applied occurs at significantly lower (up to $30 \%$ ) heat flux supplied to the heating surface, in comparison to results obtained for a plain foil.

\subsection{The impact of other parameters on heat transfer coefficient and boiling curves}

The type of applied coolant did not affect qualitatively on the course of incipience and development of boiling in minichannels. It was also found that the change in the width of the minichannel did not affect the course of the boiling process.

\section{Conclusions}

The article presents the results of flow boiling heat transfer in a minichannel of $1 \mathrm{~mm}$ depth, asymmetrically heated by enhanced foil, orientated horizontally (positions $0^{\circ}$ and $180^{\circ}$ ) and vertically (position $90^{\circ}$ ). Application of liquid crystal thermography allowed the measurement of two-dimensional temperature distribution of the heating foil. The impact of the type of the enhanced surface and channel orientation on the boiling development and flow resistance was analyzed. In detail the impact on the following: heat transfer coefficient, boiling curves and two phase pressure drop was discussed. The most important factor turned out to be channel orientation. Application of the enhanced heating surface caused the increase of the heat transfer coefficient from several to several tens per cent, in relation to the plain surface. Surfaces with micro-recesses distributed evenly allowed obtaining higher values of the heat transfer coefficient than surfaces with mini-recesses distributed unevenly. Other analyzed factors affect boiling development and pressure drop in the minichannel in the manner shown in the present paper.

\section{Acknowledgments}

The research has been financially supported by the National Scientific Center granted on the basis of decision No. DEC-2013/09/B/ST8/02825.

\section{References}

1. R. Pastuszko, M. Piasecka, J. Physics Conf. Ser. 395, No. 012137 (2012)

2. R. Pastuszko, Exp. Thermal Fluid Sci. 38, 149-164 (2012)

3. M. Piasecka, Annals Nuclear Energy 73, 282-293 (2014) 
4. N. Radek N., Ł.J. Orman, J. Bronček, A. Kapjor, Technológ, 2, Zilinska universita $\mathrm{v}$ Ziline, 99-102 (2014)

5. K. Dutkowski, Heat Transf. Eng. 31, 321-330 (2010)

6. M. Piasecka, Heat Mass Transf. 49, 261-271 (2013)

7. M. Piasecka, Int. J. Heat and Mass Transf. 66, 72-488 (2013)

8. M. Piasecka, B. Maciejewska, Exp. Thermal Fluid Sci. 44, 23-33 (2013)

9. M. Piasecka, Exp. Heat Transf. 27, 231-255 (2014)

10. M. Piasecka, Heat Transf. Eng. 35 (10), 903-912 (2014)

11. M. Piasecka, S. Hożejowska, Heat Mass Transf. 50, 1053-1063 (2014)

12. M. Piasecka, Adv. Material Research 874, 95-100 (2014)

13. M. Piasecka, Metrology and Meas. Sys. XX, 205-216 (2013)

14. M. Piasecka, Int. J. Heat and Mass Transf. 81, 114-121 (2015) 